\title{
Illusory conjunctions and the cerebral hemispheres
}

\author{
YANIK MIOSSEC \\ University of Lille III, Villeneuve d'Ascq, France \\ RÉGINE KOLINSKY \\ National Funds for Scientific Research, Brussels, Belgium \\ and Free University of Brussels, Brussels, Belgium \\ and \\ JOSÉ MORAIS \\ Free University of Brussels, Brussels, Belgium
}

\begin{abstract}
Two visual half-field experiments tested Moscovitch's (1979) proposition that cerebral asymmetry does not concern the earliest perceptual stages but only later processing. Subjects were briefly shown displays that included one (Experiment 1) or two (Experiment 2) types of forms differing in size and which, according to previous evidence, might lead to opposite laterality effects. Laterality effects were assessed for correct detections and for illusory conjunctions, both in terms of raw detection scores and in terms of perceptual discriminability ( $d^{\prime}$ scores). In Experiment 1, displays included either rectangles or triangles. In the first case, the target was a cross; in the second case, it was a Star of David. A hemifield $\times$ size interaction was observed both on correct detections and on associated discriminability. Yet, no such interaction was obtained for illusory conjunctions or for associated $d^{\prime}$ scores. In Experiment 2, the two types of forms were presented simultaneously, with the small ones either inside or outside the large ones. No laterality effects were observed. Some implications of these data for both hemispheric asymmetry and feature integration issues are discussed. The results suggest that early preattentive processes of feature extraction are not lateralized, whereas some integrative mechanisms, such as Treisman's (1988) focal attention, may operate differently in the two hemispheres.
\end{abstract}

Moscovitch (1979) proposed that the cerebral hemispheres are functionally symmetrical at the earliest perceptual stages and that laterality differences emerge at later stages. However, assessing the functional symmetry of early processing is a difficult task. First, it implies acceptance of the null hypothesis (i.e., no laterality effect), which is always a very uncomfortable situation. Such a negative result should be contrasted to positive results (i.e., asymmetry) obtained in the same experimental situation. In other words, the experimental design should allow laterality differences to either emerge or not emerge

The first author benefited from a Fyssen Foundation grant during the execution of the present work. The second author had a grant from the Belgian Services de Programmation de la Politique Scientifique (SPPS), Programme d'Impulsion à l'Intelligence Artificielle, Convention $\mathbf{n}^{\circ}$ RFO/AI/23. She is presently Research Associate of the Belgian Fond National de la Recherche Scientifique. The present research was also partially subsidized by the Belgian Fonds de la Recherche Fondamentale Collective (FRFC) under Convention $n^{\circ} 2.4562 .86$. We want to thank the editor of this paper, L. E. Krueger, as well as three anonymous reviewers, for their very detailed and theoretically oriented comments, which led us to improve substantially the quality of this paper. Reprint requests may be sent to the first author at LABACOLIL, Université de Lille III, 59653 Villeneuve d'Ascq, France, or to the third author at Laboratoire de Psychologie Expérimentale, Université Libre de Bruxelles, 117, av. A. Buyl, 1050 Bruxelles, Belgium. as a function of processing stage. The second, even more important, difficulty is that the characterization of early processing has for a long time been impeded by methodological limitations-namely, that early stages cannot be directly accessed, either by introspection or by instrumental responses (Fodor, 1983; Marcel, 1983; Treisman, 1986a). Yet some indirect ways of studying early processing have been proposed and developed in the last 10 years. The present study attempted to test Moscovitch's hypothesis by using such an indirect approach-namely, the illusory conjunction phenomenon-and by contrasting it with more traditional measures of performance, which probably reflect later processing stages.

The illusory conjunction (ICs) phenomenon was first observed by Treisman and Schmidt (1982). When a display consisting of blue As and red Bs is briefly flashed with masking before and after presentation, observers quite often may report to have seen a blue B or a red A. Those errors in which the features, but not their combination, are correct occur more frequently than do simple feature misperceptions (e.g. , a green A or a blue D). ICs were actually predicted by Anne Treisman's theory of object perception, which involves two stages of processingthat is, a stage of feature extraction followed by a stage of feature integration (Treisman, 1988; Treisman \& Gelade, 
1980). Simple features (such as color, segments, orientation, etc.) are supposed to be extracted in parallel at the first processing stage. Then, at the second stage, the features would be serially integrated into multidimensional objects. Co-occurrence in time and place of the already detected features would make them "glue" together. The early stage is assumed to be preattentive or automatic, whereas the second, which implies a serial scanning of each discontinuity detected in the visual field, would require focal attention. ICs would be observed when task conditions selectively prevent attention from correctly integrating the previously extracted features (Treisman \& Paterson, 1984; Treisman \& Schmidt, 1982).

ICs reflect relatively early processing of feature extraction, followed by some "automatic" (and incorrect), by-default binding. How early these operations are in perceptual processing is a matter for discussion (cf. Houck \& Hoffman, 1986; Kolinsky, 1988, 1989). Yet according to Treisman's (1986b) theory, ICs arise without the intervention of focal attention, since by definition it is precisely attentional serial scanning that allows correct feature integration. In other words, correct integration and ICs share the same perceptual processes except for what concerns the mechanism of focal attention. Correct integration results from the action of this mechanism, whereas ICs arise when focal attention is prevented from acting efficiently. Under this view, ICs undoubtedly reflect more primitive, less complex mechanisms than does the correct perception of objects.

According to Moscovitch's (1979) hypothesis, one may thus expect ICs of the display features to occur evenly in the two hemifields, despite the occurrence of a laterality effect for correct perceptions. Such a pattern of results would indicate that what is lateralized is the mechanism of integration, perhaps the focal attention mechanism proposed by Treisman (1986b).

The basic idea of the present study is to inspect both ICs and correct perceptions for the occurrence of laterality effects. To obtain unequivocal evidence on the laterality issue, we used two different materials that, according to previous evidence, might lead to opposite laterality effects for correct identification. Thus, the aim of the present study was to assess whether or not ICs and correct perceptions show the same laterality pattern in a situation in which correct perception of one type of material may be presumed to rely mainly on left hemisphere processing (directly accessed by the right visual field) and correct perception of the other material may be presumed to rely mainly on right hemisphere processing (directly accessed by the left visual field).

To obtain laterality effects on (at least) correct perceptions, we manipulated the size of simple geometrical forms. We assumed that, in principle, the larger the form, the greater the involvement of the right hemisphere compared with the left. This size manipulation was applied to two different kinds of forms: isosceles triangles pointing either to the top or to the bottom and rectangles laid either on their large or on their narrow side. These two types of displays may lead one to illusorily perceive either a Star of David or a cross, respectively (see examples in Figures $1 a, 1 b, 1 c$ and $\left.1 a^{\prime}, 1 b^{\prime}, 1 c^{\prime}\right)$. Sergent (1982) obtained the predicted change in laterality effects for forms subtending visual angles similar to the ones we used (see Van Kleeck, 1989). Although size effects may possibly be interpreted in the context of the spatial frequency approach of laterality differences (Sergent, 1982), we wish to state that testing this notion was not a purpose of the present study.

Before the present work, only one published study, to the best of our knowledge, dealt with the question of hemifield differences in ICs. Eglin (1987) presented the observers in either the left or the right visual field (LVF and RVF, respectively) with a column of three colored letters and two items that were either two digits (Experiment 1) or two triangles pointing in the same or different directions (Experiment 2). Observers were required to report first either the digits or the direction of the triangles, and then to report as many features of the letters as they could. The most interesting aspects of the results are the following. First, the total number of letter features (identity and color) correctly reported was greater in the RVF, whatever the primary task. Thus, extraction of the component features of the letters seems to be independent of the amount of capacity left available in each hemisphere by the accomplishment of the primary task. Second, correct combinations of identity and color of the letters were more numerous in the RVF than in the LVF when the primary task concerned the triangles, but there was no hemifield difference when the primary task concerned the digits. Accordingly, there was an interaction between primary task and hemifield regarding the proportion of ICs relative to all conjunctions of correct features. This proportion was higher in the LVF when the primary task was done on the triangles and in the RVF when the primary task was done on the digits.

Thus, the efficiency of feature integration appears to depend on the amount of resources left available in each

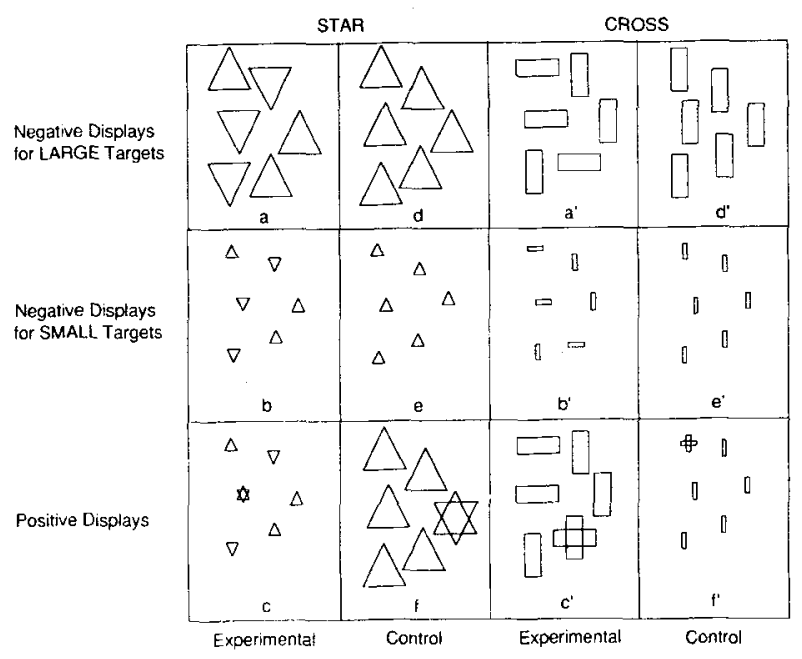

Figure 1. Examples of displays used in Experiment 1. 
hemisphere by the primary task. The spatial (right hemisphere prevalent) primary task apparently spared more capacity in the left hemisphere for the correct integration of the letters features than did the verbal (left hemisphere prevalent) primary task. For Eglin (1987), feature integration may be the first and only perceptual processing stage at which there is intrahemispheric competition for attentional resources with the primary task. This competition may be the source of asymmetries in perceptual performance. Eglin's findings are impressive, because they suggest a dissociation between feature extraction and integration in their relation to attentional resources, which supports Treisman's (1986b) feature-integration theory of attention. However, there are two aspects of her study that invite caution. First, given the use of a multiple-item identification task, and given the possible deleterious effects of the primary task on retention of the perceived letters, one can hardly be sure that the results observed by Eglin (1987) for feature conjoining had their origin during the elaboration of the percept rather than during the time that elapsed between the percept and its report. Second, although Eglin's study measured laterality differences, it was actually insufficient to answer the question, "what are the earlier lateralized stages in visual processing?" She rightly interpreted her results as suggesting that the integration of features by focal attention is achieved by the hemisphere of input. However, she added that "the conjunction process cannot be lateralized to one hemisphere. Serial, attended processing is carried out in both hemispheres. Its efficiency is dependent upon the amount of resources available in each hemisphere" (Eglin, p. 84). We think that this inference is not at all warranted. To assess whether or not feature recombination is to some extent a lateralized process, it is necessary to manipulate either the characteristics of the stimuli, which is what we do in the present experiments, or the nature of the task carried out on these stimuli. Indeed, asking if the integration process is lateralized without specifying which features of which stimuli are involved in this process may be superfluous.

As far as we know, the only study that directly addressed Moscovitch's (1979) hypothesis on the distinction between preattentive and integrative, attentional, processes was the one designed by Palmer and Tzeng (1990). Using samedifferent reaction-time judgments of laterally presented arrays of either "popout" or "nonpopout" stimuli of the same type as previously studied by Treisman (Treisman \& Gormican, 1988, Experiment 5; Treisman \& Souther, 1985, Experiment 1), these authors observed hemifield differences, in both errors and reaction times, on materials supposedly requiring attentive processing-that is, showing an effect of array size. No laterality difference emerged in the condition in which popout stimuli led to almost flat error rates and reaction times-that is, in which processing is supposed to be parallel and preattentive. However, although attractive, the interpretation of arraysize independent versus array-size dependent effects as reflecting parallel, preattentive processing versus atten- tional, serial processing, respectively, has been widely criticized (see, e.g., Quinlan \& Humphreys, 1987; Townsend, 1971, 1972; Townsend \& Ashby, 1983). Besides, the hypothesis that only simple feature processing leads to flat search curves and that all conjunctions of features lead to array-size dependent curves has been debated for the last 5 years (see, e.g., Chmiel, 1989; Duncan \& Humphreys, 1989, 1992; Mordkoff, Yantis, \& Egeth, 1990; Quinlan \& Humphreys, 1987; Treisman, 1991, 1992; Treisman \& Sato, 1990; Wolfe, Cave, \& Franzel, 1989). Hence, a much more straightforward way to distinguish between pre- and postintegrated percepts is to compare illusory percepts with correct perceptions.

Since, as already noted, ICs may sometimes result merely from trace interference during recall (Kolinsky, 1988, 1989; Schooler \& Tanaka, 1991; Tippens Reinitz, Lammers, \& Pitts Cochran, 1992; Treisman, Sykes, \& Gelade, 1977), in the present study, we preferred to use a single target-detection task, which minimized memory load. In such a detection situation, ICs are indicated by the occurrence of incorrect detections (henceforth, false detections, or FDs) of the target on target-absent trials. More precisely, given the possibly large number of simple misperceptions, ICs are estimated by comparing target FDs made on target-absent experimental trials, in which all the information necessary to perceive the target is present, although not in the same object, with FDs made on target-absent control trials, in which one of the target's attributes is missing. As can be seen in Figure 1, target-absent experimental displays always contained two differently oriented forms (either triangles, as in Figures $1 \mathrm{a}$ and $1 \mathrm{~b}$, or rectangles, as in Figures $1 a^{\prime}$ and $1 b^{\prime}$ ), whereas control displays only contained similarly oriented forms (either triangles all pointing up, as in Figures 1d and le, or down, or rectangles vertically, as in Figures 1d' and $1 \mathrm{e}^{\prime}$, or horizontally presented). Since the excess of FDs on experimental displays, compared with FDs on control displays, cannot be attributed to simple attribute misperceptions, it is assumed to reflect the real number of ICs. Of course, correct integration is estimated as the correct detections (CDs) of the target on corresponding target-present trials (see examples in Figures 1c, 1f, 1c', and $\left.1 f^{\prime}\right)$.

Yet, even in such a simple detection situation, both CDs and ICs may result from decision bias (Kolinsky, 1988, 1989; Treisman \& Souther, 1986). Thus, rather than directly comparing raw FD and CD scores with regard to laterality effects, we also used the signal detection theory bias-free index of discriminability, $d^{\prime}$ (see, e.g., Green \& Swets, 1966). By taking both CD and FD levels into account, $d^{\prime}$ measures the separation between the internal representation of the stimuli and the noise in units of standard deviation, independently of subjects' response criterion. It is thus a relatively pure index of the subject's ability to distinguish target presence from target absence. The $d^{\prime}$ scores were calculated for each subject from the CD and FD scores, independently for experimental and control displays, and separately for each type of material. 
Since higher $d^{\prime}$ scores reflect better discriminability, and since we supposed larger forms to be better processed by the right hemisphere and smaller forms by the left hemisphere, we expected not only CDs but also overall $d^{\prime}$ scores, irrespective of the type of trial, to be higher in the LVF than in the RVF for the large forms, and to present the opposite laterality pattern for the small forms.

At the level of discriminability, ICs were estimated as the difference between the $d^{\prime}$ scores obtained on experimental trials and the $d^{\prime}$ scores obtained on control trials (see Kolinsky, 1988, 1989, and Treisman \& Souther, 1986, for similar estimation methods). If ICs reflect a loss of discriminability, we expect $d^{\prime}$ scores to be lower for experimental than for control displays. With regard to laterality effects, ICs and the corresponding differential $d^{\prime}$ scores would show the same laterality pattern as would CDs and the overall $d^{\prime}$ scores if the processes involved in ICs and attentive feature integration were lateralized in the same way. Alternatively, if, as suggested by Moscovitch (1979), only later processing stages are lateralized, field effects should be observed only for CDs and overall discriminability, as reflected by $d^{\prime}$ scores, and not at all for ICs and their corresponding differential $d^{\prime}$ scores.

\section{EXPERIMENT 1}

In Experiment 1, the target was either a Star of David or a cross, for the triangle and rectangle material, respectively. Each target-absent display contained either only triangles or only rectangles, and each target-present display contained either only triangles plus a Star of David or only rectangles plus a cross. Size was counterbalanced across materials to ensure that it was actually the crucial factor in the laterality effect. However, size of the target and of the forms presented on the displays were always congruent. Thus, in one condition, the small material and target consisted of rectangles and crosses, and the large material and target consisted of triangles and Stars of David. In the other condition, the reverse situation was used (i.e., large crosses and rectangles, and small stars and triangles; see examples in Figure 1).

\section{Method}

Subjects. The subjects were 32 female undergraduate students, with a mean age of 20.8 years (range 18-33 years). All were right-handed as measured by Hécaen's (1984) questionnaire, had normal or corrected-to-normal vision as self-reported, and were naive concerning the purpose of the experiment.

Apparatus and Stimulus Materials. The stimuli were presented in an Electronic Developments three-field tachistoscope. The distance between the eyes of the subject and the display was $57 \mathrm{~cm}$. The targetabsent displays consisted of six forms that were either rectangles or isosceles triangles and either small or large. There were thus four possibilities: six small rectangles (each $0.2^{\circ} \times 0.5^{\circ}$ ), six small triangles, (each $0.5^{\circ}$ wide $\times 0.5^{\circ}$ high), six large rectangles (each $0.8^{\circ}$ $\times 2^{\circ}$ ), and six large triangles (each $2^{\circ}$ wide $\times 2^{\circ}$ high). In the control displays (C), all of the rectangles were presented in the same orientation. They were presented horizontally (i.e., laid on their large side) in half of the target-absent control displays and vertically (i.e., laid on their narrow side) in the other half. Similarly, all of the triangles involved in the control conditions pointed in the same direction.
All of the triangles pointed to the top in half of the target-absent control displays, whereas they pointed to the bottom in the other half. In the experimental displays (E), three rectangles (or triangles) were presented in one orientation, and three rectangles (or triangles) were presented in the other orientation. The figures were drawn in black ink on white cards with a $0.5-\mathrm{mm}$ pen for large figures and a 0.2 $\mathrm{mm}$ pen for the small ones.

In the triangle-display condition, the target was a Star of David formed by the superposition of two triangles pointing in opposite directions; in the rectangle-display condition, the target was a cross formed by the superposition of two rectangles, a horizontal and a vertical one. Target-present trials constituted $30 \%$ of all trials. The target replaced any one of the six forms used in the target-absent trials. The whole displays were centered either at the fixation point or at $3.8^{\circ}$ to the left or to the right of it, so that in the lateral presentations, the inner side of the display was $1^{\circ}$ from the fixation point.

The subjects were divided into two equal groups, each one concerned with only two material conditions. One group was presented with rectangles and a cross as small material, and with triangles and a Star of David as large material. Conversely, the other group received large rectangles and a cross, and also received small triangles and a Star of David.

The first half of the session was devoted to one target; the second half of the session was devoted to the other target. The entire session lasted about $90 \mathrm{~min}$. For each target, there were three trial blocks. Each block consisted of 80 trials: 28 target-absent $E$ trials $(E-), 28$ target-absent $C$ trials $(C-), 12$ target-present $E$ trials $(E+)$, and 12 target-present $C$ trials $(C+)$. Two of these blocks (160 trials), which were run successively, were used for unpredictable LVF and RVF presentations. Given that the eccentricity of relatively extended displays presented laterally could be inappropriate to the occurrence of ICs, the third block was used in a central presentation condition ( 80 trials). These central presentation trials were blocked to avoid interference with the psychophysical staircase procedure used to determine exposure durations for the lateral presentations. ${ }^{1}$ Trials within a block were presented pseudorandomly, with the constraint that the same type of trial and, for lateral presentation, the same position of the display in the visual field could appear no more than three times in succession. For the lateral presentations, each card was presented twice, with the display once to the left and once to the right, by turning the set of 80 cards upside down between the two blocks. Thus, a complete equivalency was obtained concerning both target positions and trials succession.

Procedure. The experimenter gave a verbal signal and pressed a button to initiate each trial and trigger the timer. The displays were preceded and followed by a random black-and-white checkerboard mask exposed for $600 \mathrm{msec}$. The observers were asked to indicate on each trial whether or not the target was present. They responded by pressing either a "yes" switch controlled by one hand or a "no" switch controlled by the other hand. The mode of response was the same throughout the entire session. The two switches, $10 \mathrm{~cm}$ apart, were placed in the median plane. The switch-pressing stopped the chronometer.

The subjects were first shown a card with the target. Forty additional trials of practice were given. Exposure time gradually decreased from $500 \mathrm{msec}$ to $60 \mathrm{msec}$, with this duration used at the beginning of the first experimental block. Then, exposure duration was adjusted according to the following procedure. After seven correct responses, it was decreased by $10 \mathrm{msec}$; after an error, it was increased by $10 \mathrm{msec}$. For this procedure, all of the trials were taken into account except those in which the observer made an FD on E- trials. The maximum exposure duration allowed was $190 \mathrm{msec}$. The subjects were told both to respond as fast as possible while making as few errors as possible, and to make a response on every trial. Within each group of subjects, order of both materials and targets (triangles and stars on the one hand, and rectangles and crosses on the other hand) and of lateral and central presentations, as well as hand of "yes" response, were counterbalanced between subjects. 
Table 1

Experiment 1: Mean Percentage of Faise Detections (FD) and of Correct Target Detections (CD), Mean $d^{\prime}$ and Beta Scores for Each Type of Display, and Mean Estimates of Illusory Conjunctions (IC), in Left (LVF) and Right (RVF) Visual Fields and for Each Target

\begin{tabular}{|c|c|c|c|c|c|c|c|c|c|c|c|c|c|c|c|c|}
\hline \multirow[b]{3}{*}{ Type of Display } & \multicolumn{8}{|c|}{ LVF } & \multicolumn{8}{|c|}{ RVF } \\
\hline & \multicolumn{2}{|c|}{ FD } & \multicolumn{2}{|c|}{$\mathrm{CD}$} & \multicolumn{2}{|c|}{$d^{\prime}$} & \multicolumn{2}{|c|}{ Beta } & \multicolumn{2}{|c|}{ FD } & \multicolumn{2}{|c|}{$\mathrm{CD}$} & \multicolumn{2}{|c|}{$d^{\prime}$} & \multicolumn{2}{|c|}{ Beta } \\
\hline & $M$ & $S D$ & $M$ & $S D$ & $M$ & $S D$ & $M$ & $S D$ & $M$ & $\overline{S D}$ & $M$ & $S \bar{D}$ & $M$ & $S D$ & $M$ & $S D$ \\
\hline $\begin{array}{l}\text { Star } \\
\text { E large cross }\end{array}$ & $\begin{array}{l}20.1 \\
21.5\end{array}$ & & $\begin{array}{l}79.8 \\
78.4\end{array}$ & & $\begin{array}{l}2.05 \\
1.76\end{array}$ & & $\begin{array}{l}1.29 \\
1.06\end{array}$ & & $\begin{array}{l}22.7 \\
25.4\end{array}$ & & $\begin{array}{l}73.9 \\
74.7\end{array}$ & & $\begin{array}{l}1.78 \\
1.54\end{array}$ & & $\begin{array}{l}1.04 \\
1.00\end{array}$ & \\
\hline All & 20.8 & 15.7 & 79.2 & 10.8 & 1.91 & 0.62 & 1.17 & 3.70 & 24.1 & 17.5 & 74.3 & 15.4 & 1.66 & 0.64 & 1.02 & 3.74 \\
\hline $\begin{array}{l}\text { Star } \\
\text { C large cross }\end{array}$ & $\begin{array}{r}11.6 \\
7.7\end{array}$ & & $\begin{array}{l}78.8 \\
72.1\end{array}$ & & $\begin{array}{l}2.29 \\
2.45\end{array}$ & & $\begin{array}{l}1.82 \\
2.98\end{array}$ & & $\begin{array}{l}10.9 \\
12.1\end{array}$ & & $\begin{array}{l}70.8 \\
72.4\end{array}$ & & $\begin{array}{l}2.11 \\
2.09\end{array}$ & & $\begin{array}{l}2.23 \\
1.97\end{array}$ & \\
\hline All & 9.7 & 10.8 & 75.4 & 17 & 2.37 & 0.52 & 2.32 & 4.71 & 11.5 & 11 & 71.6 & 17.7 & 2.10 & 0.55 & 2.10 & 3.93 \\
\hline IC & $11.1^{*}$ & 11.6 & & & $0.46^{*}$ & 0.77 & & & $12.7^{*}$ & 10.8 & & & $0.44^{*}$ & 0.71 & & \\
\hline $\begin{array}{l}\text { Star } \\
\text { E small cross }\end{array}$ & $\begin{array}{l}17.9 \\
27.1\end{array}$ & . & $\begin{array}{l}70.9 \\
80.6\end{array}$ & & $\begin{array}{l}1.73 \\
1.71\end{array}$ & & $\begin{array}{l}0.76 \\
1.91\end{array}$ & & $\begin{array}{l}19.3 \\
32.6\end{array}$ & & $\begin{array}{l}75.7 \\
88.1\end{array}$ & & $\begin{array}{l}1.9 \\
1.99\end{array}$ & & $\begin{array}{l}0.38 \\
1.11\end{array}$ & \\
\hline All & 22.5 & 18.6 & 75.8 & 14.4 & 1.72 & 0.55 & 1.21 & 2.97 & 25.9 & 19.6 & 81.9 & 16.8 & 1.95 & 0.69 & 0.65 & 4.35 \\
\hline $\begin{array}{l}\text { Star } \\
\text { C small cross }\end{array}$ & $\begin{array}{l}12.8 \\
21\end{array}$ & & $\begin{array}{l}75.6 \\
81.6\end{array}$ & & $\begin{array}{l}2.16 \\
2.12\end{array}$ & & $\begin{array}{l}0.75 \\
1.44\end{array}$ & & $\begin{array}{l}17.9 \\
21.4\end{array}$ & & $\begin{array}{l}77.1 \\
89.1\end{array}$ & & $\begin{array}{l}2.01 \\
2.46\end{array}$ & & $\begin{array}{l}0.41 \\
1.00\end{array}$ & \\
\hline All & 16.9 & 14.3 & 78.6 & 17.1 & 2.14 & 0.6 & 1.04 & 4.62 & 19.7 & 13.6 & 83.1 & 15.7 & 2.23 & 0.69 & 0.64 & 4.76 \\
\hline IC & $5.6^{*}$ & 10.7 & & & $0.42 *$ & 0.9 & & & $6.3^{*}$ & 13.8 & & & $0.28+$ & 1.03 & & \\
\hline
\end{tabular}

Note-E $=$ experimental displays, $\mathrm{C}=$ control displays, $\mathrm{IC}=$ illusory conjunctions. $\quad{ }^{*} p<.001 . \quad \dagger p<.06$.

The mean exposure duration was $121 \mathrm{msec}$ for lateral presentations. It was faster for large targets $(108 \mathrm{msec})$ than for small ones $[133 \mathrm{msec}, t(31)=6.86, p<.001]$.

ICs were experienced with central presentation, as observed on $d^{\prime}$ scores [1.99 for $E$ vs. 2.22 for $C$ displays; $t(30)=2.52, p<.02$ ] as well as on FDs $[23.7 \%$ for $\mathrm{E}$ vs. $17 \%$ for $\mathrm{C}$ displays; $t(30)=$ $4.92, p<.001]$.

\section{Results}

$d^{\prime}$ scores. The $d^{\prime}$ scores are presented in Table 1, separately for each form material, size, and display type. ${ }^{2,3} \mathrm{An}$ analysis of variance (ANOVA) of group (i.e., material condition: large triangles and small rectangles in Group 1 vs. small triangles and large rectangles in Group 2) $\times$ display type ( $\mathrm{E}$ vs. $\mathrm{C}$ displays) $\times$ visual field (RVF vs. $L V F) \times$ size (large vs. small materials) was performed. The $d^{\prime}$ scores were smaller for $\mathrm{E}$ (mean: 1.81) than for $\mathrm{C}$ (mean: 2.21 ) displays $[F(1,30)=20.90, p<.001]$. As shown in Table 1 , this display type effect was significant for each combination of size and hemifield. There was no main effect of size or of hemifield ( $F<1$ for both), but the expected interaction hemifield $\times$ size was significant $[F(1,30)=$ 9.93, $p<.004]$. Indeed, in the LVF, the large material yielded higher $d^{\prime}$ scores (averaging over $\mathrm{E}$ and $\mathrm{C}$ trials: $2.14)$ than did the small material [average: $1.93 ; F(1,30)=$ $4.6, p<.05]$, whereas the opposite pattern was observed in the $\operatorname{RVF}[F(1,30)=5.53, p<.03]$, in which the small material yielded higher $d^{\prime}$ scores (average: 2.09 ) than did the large one (average: 1.88). This interaction is shown in Figure 2. No other interaction was significant. In particular, the interaction display type $\times$ size $\times$ hemifield, which tests for laterality effects on ICs, did not show any trend toward significance $(F<1)$. In addition, no interaction involving group was significant.

Correct detections. Mean CDs are also presented in Table 1. An ANOVA was performed on CDs, with the same factors as in the $d^{\prime}$ analysis. The small material yielded higher $\mathrm{CD}$ scores than did the large material $[79.9 \%$ vs. $75.1 \%$, respectively; $F(1,30)=5.52, p<.03]$. The interaction hemifield $\times$ size observed on overall $d^{\prime}$ scores was also obtained on $\operatorname{CDs}[F(1,30)=8.82, p<.006]$ : small targets were better detected in the RVF (mean: 82.5\%) than in the LVF (mean: $77.2 \%$ ), whereas large targets yielded higher CD scores in the LVF (mean: $77.3 \%$ ) than in the RVF (mean: $72.9 \%$ ). There was also a group $\times$ size interaction $[F(1,30)=4.55, p<.05]$, which was due to better performance of Group 1 with the small cross target $(84.9 \%)$ than with the large star target $(75.9 \%)$, contrasting with no difference between the two targets in Group 2 (74.4\% for the large cross; $74.8 \%$ for the small star). How-

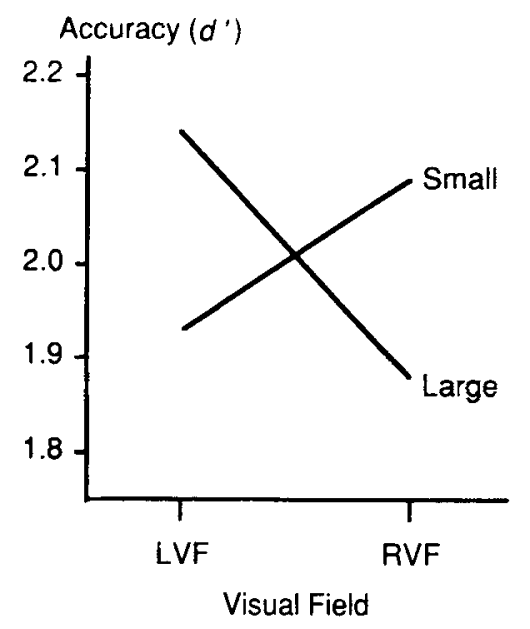

Figure 2. Mean d' scores obtained in Experiment 1 for small and large targets as function of left and right hemifields. 
ever, as for the $d^{\prime}$ scores, the group $\times$ hemifield interaction was far from significance $(F<1)$.

False detections and illusory conjunctions. Table 1 presents mean FDs and mean IC estimates. ICs represent the difference between the FDs obtained on the $E$ and $C$ displays. An ANOVA was performed on FDs, with the same factors as in previous analyses. The display type effect was significant $[F(1,30)=53.6, p<.001]$ : FDs were more frequent in $\mathrm{E}(23.3 \%)$ than in $\mathrm{C}(14.4 \%)$ displays, indicating occurrence of ICs. As shown in Table 1, the estimate of ICs was significant for each combination of size and hemifield. There were more ICs with large targets $(11.9 \%)$ than with small ones $(5.9 \%)$, as indicated by the size $\times$ display type interaction $[F(1,30)=8.14, p<$ $.008]$. The interaction size $\times$ group was also significant $[F(1,30)=4.58, p<.05]$. Group 1 falsely detected (on both $\mathrm{E}$ and $\mathrm{C}$ displays) more small crosses $(25.5 \%)$ than large stars $(16.3 \%)$, whereas Group 2 did not exhibit this difference ( $16.7 \%$ for large crosses; $16.9 \%$ for small stars).

\section{Discussion}

Experiment 1 showed the expected interaction between target and lateral visual field at the level of overall perceptual discriminability. This interaction was also obtained on CDs: Small targets tended to be more often correctly detected in the RVF than in the LVF, thus suggesting a left-hemisphere superiority, whereas the reverse trend was observed for large targets. The absence of a group of subjects $\times$ hemifield interaction supports the idea that the laterality pattern is actually due to size, not to form. These results are consistent with the idea that the processing of small and large forms is more efficient in the left and in the right hemispheres, respectively.

ICs were not affected by material size. More important for our purpose here, ICs did not differ between the two hemifields and did not exhibit the interaction between size and hemifield that came out on CDs. The analysis of $d^{\prime}$ scores, showing an interaction between hemifield and size, but not between display type, size, and hemifield, reinforces the notion that overall discriminability, contrary to the IC phenomenon, does depend on laterality. This suggests that the inferred superior ability of the left and the right hemispheres to deal specifically with small and large targets, respectively, has no relation with the extraction of features and their subsequent by-default binding. These processes, which in all likelihood are realized before correct integrative mechanisms intervene, seem to operate in either hemisphere with equal competence, regardless of form size.

\section{EXPERIMENT 2}

The results of Experiment 1 suggest that the two hemispheres differ in terms of the spatial scales on which they can integrate featural visual information. The left and the right hemispheres would integrate features subtending smaller and larger visual angles, respectively. It is important to remark that each display contained either large forms only or small forms only, so that integration could occur at only one spatial scale. This kind of display, by triggering more activation of the integrative mechanism in one hemisphere than in the other, may have contributed to the finding of a hemifield difference.

However, this is not the only possible explanation. Indeed, the task implies determining whether or not a target of a particular size is displayed among other forms. Thus, it is important to distinguish between an unbalanced hemispheric activation of the integrative mechanisms due to the presentation of either small or large forms only, and an unbalanced hemispheric activation due to the size of the target. To distinguish between these two alternatives, in Experiment 2 we presented simultaneously large and small forms in the same display. The integrative mechanisms presumably operate regardless of the observers' intentions and aims. Thus, in Experiment 2, they should operate at both spatial scales, leading to similar levels of activation in the two hemispheres. If it was the unbalanced activation of these mechanisms that was responsible for the hemifield differences observed in Experiment 1 , these differences should at least be considerably reduced in Experiment 2 . If, on the contrary, the hemifield differences were due to the fact that the observer had to detect a target of a particular size, the hemifield differences should still be observed in Experiment 2.

Experiment 2 was designed to allow a joint statistical analysis of the two experiments. Our main interest was to use displays that simultaneously presented figures of different sizes. However, since ICs may possibly occur independently of the exact sizes of the figures (Treisman \& Schmidt, 1982, Experiment 4), and since the results of Experiment 1 clearly showed that the relevant factor for the laterality effect was size and not form, we preferred to use different forms for large and small figures. We thus used displays that were heterogeneous with regard to both the forms and the sizes presented. They included simultaneously small rectangles and large triangles, even if, as in Experiment 1, only one size was relevant to the task. To control for organizational or grouping effects (see, e.g., Duncan \& Humphreys, 1989; Humphreys, Quinlan, \& Riddoch, 1989; Humphreys, Riddoch, \& Quinlan, 1985; Kahneman \& Henik, 1977, 1981; Pashler \& Badgio, 1985), we designed two heterogeneous conditions. In one condition, small rectangles were drawn inside the large triangles (see the examples in Figures 3a, 3c, 3e, and 3g), whereas in the other condition, small rectangles were drawn outside the large triangles (see the examples in Figures 3b, 3d, 3f, and 3h). In contrast to stimuli of the outside condition, those of the inside condition probably appear not only more organized but also less numerous.

Relations between the forms were also manipulated in a second fashion, which was concerned with the variability of the irrelevant forms-that is, the rectangles in the stardetection task and the triangles in the cross-detection task. In one condition, that of similarly oriented context, all of the irrelevant forms were in the same orientation (e.g., 


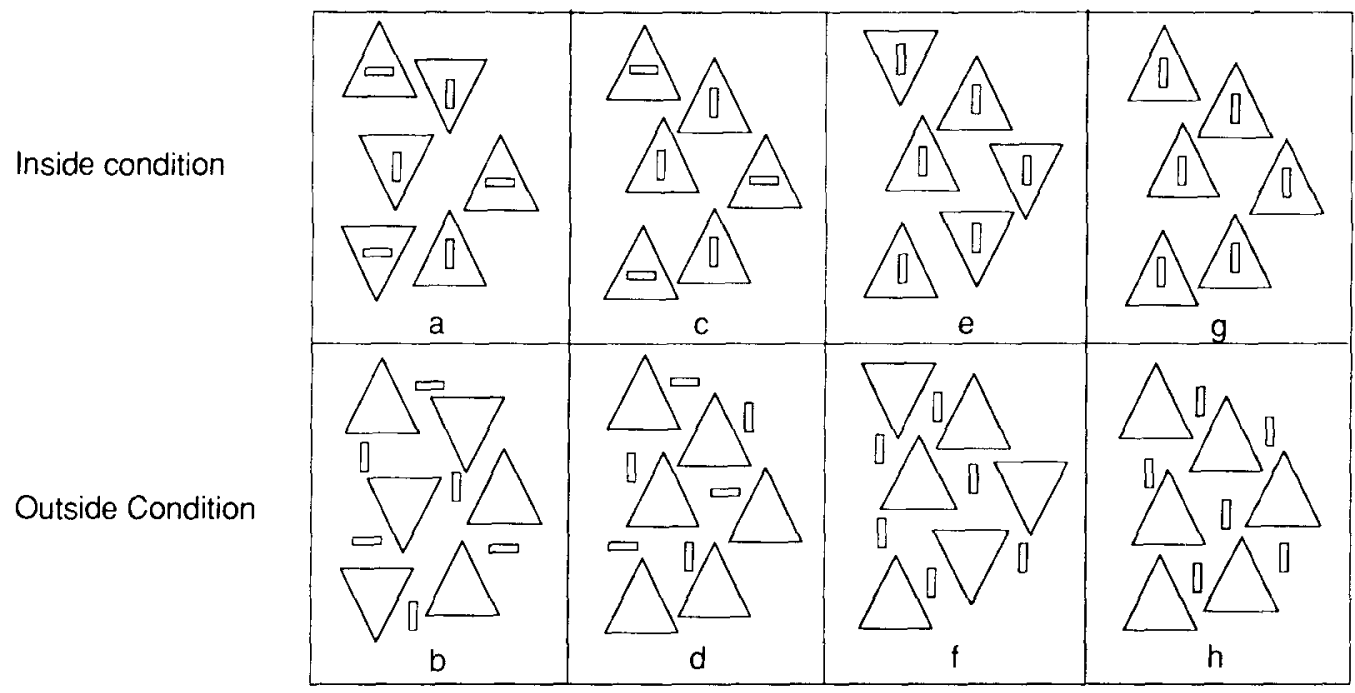

a, b: negative experimental displays with differentially oriented context in both target conditions

c, d: negative experimental display with similarly oriented context in small cross target condition or negative control display with differentially oriented context in large star target condition

$e, f$ : negative control display with differentially oriented context in small cross target condition or negative experimental display with similarly oriented context in large star target condition

$\mathrm{g}, \mathrm{h}$ : negative control displays with similarly oriented context in both target conditions

Figure 3. Examples of displays used in Experiment 2.

in the cross-detection task, all of the triangles pointed up; see Figure 3c); in the other condition, that of differentially oriented context, half of the irrelevant forms were in one orientation, and the other half were in the other orientation (e.g., with the cross as target, three triangles pointed up and three triangles pointed down; see Figure $3 a$ ). If no filtering is possible, variability of the context forms is expected to affect performance.

\section{Method}

Subjects. The subjects were 32 female and 16 male undergraduate students (mean age: 20.8 , range 18-35). All of them satisfied the same conditions as did the subjects of Experiment 1 .

Stimulus Materials and Procedure. The dimensions of the stimuli and constitution of the $\mathrm{E}$ and $\mathrm{C}$ displays were identical to those of Experiment 1, except for the fact that only large triangles and small rectangles were used, and were presented simultaneously on the same displays, which thus contained 12 forms. Hence, in the large-star target condition, both $\mathrm{E}$ and $\mathrm{C}$ displays presented 6 large triangles as well as 6 (irrelevant) small rectangles. The difference between $\mathrm{E}$ and $\mathrm{C}$ displays for this large-star target condition was due to the fact that, as in Experiment 1, E displays presented three triangles pointing down and three triangles pointing up (Figures 3a, $3 \mathrm{~b}, 3 \mathrm{e}$, and $3 \mathrm{f}$, whereas in $\mathrm{C}$ displays, all of the triangles pointed to the same direction (Figures $3 \mathrm{c}, 3 \mathrm{~d}, 3 \mathrm{~g}$, and $3 \mathrm{~h}$ ). Similarly, in the small-cross target condition, both $\mathrm{E}$ and $\mathrm{C}$ displays contained 6 small rectangles as well as 6 (irrelevant) large triangles. As in Experiment 1, $\mathrm{E}$ displays in the small-cross target condition presented 3 rectangles laid on their narrow side and 3 rectangles laid on their large side (Figures $3 a, 3 b, 3 c$, and $3 d$ ), whereas the orientation of the 6 rectangles was identical in $\mathrm{C}$ displays (Figures $3 \mathrm{e}$, $3 \mathrm{f}, 3 \mathrm{~g}$, and $3 \mathrm{~h}$ ). The irrelevant forms (i.e., the small rectangles in the large-star target condition and the large triangles in the smallcross target condition) were in the same orientation for half of the trials (similarly oriented context) and in different orientations for the other half (differentially oriented context). In addition, there were two conditions, each one corresponding to a different group of 24 subjects. For one group, the small rectangles were placed inside the large triangles (Figures $3 \mathrm{a}, 3 \mathrm{c}, 3 \mathrm{e}$, and $3 \mathrm{~g}$ ); for the other group, the small rectangles were placed outside the large triangles (Figures 3b, 3d, 3f, and 3h). Composition of blocks of trials was identical to that in Experiment 1. In order to have as many observations as in Experiment 1, in each condition of orientation of the irrelevant forms (similarly vs. differentially oriented context), there were twice as many trials in Experiment 2. Thus, there were two blocks ( 160 trials) for central presentation and four blocks ( 320 trials) for lateral presentation. The second block, for both the central and lateral presentations, and the fourth block, for lateral presentations, were obtained by turning upside down the set of 80 cards of the first and third blocks, respectively, to obtain a complete equivalency concerning target positions and trials. The procedure was identical to that in Experiment 1, except that exposure duration at the beginning of the experimental session was set to $100 \mathrm{msec}$.

Mean exposure duration was $135 \mathrm{msec}$ for lateral presentations. For lateral presentations, there was no significant difference between the small-cross target condition and the large-star target condition [136 msec vs. $134 \mathrm{msec}$, respectively; $t(47)=1.09, p>$ $.10]$, or between groups, that is, position conditions [137 $\mathrm{msec}$ for the outside condition vs. $133 \mathrm{msec}$ for the inside condition; $t(46)=$ $1.15, p>.10$ ].

ICs occurred in central presentation, as observed on both $d^{\prime}$ scores [2.24 for E displays vs. 2.66 for $\mathrm{C}$ displays; $t(47)=7.67, p<$ $.001]$ and FDs $[22.7 \%$ for $\mathrm{E}$ displays vs. $13.7 \%$ for $\mathrm{C}$ displays; $t(47)=9.86, p<.001]$.

\section{Results}

$d^{\prime}$ scores. Table 2 presents the $d^{\prime}$ scores. An ANOVA of position (rectangles outside vs. inside triangles) $\times$ context (similarly vs. differentially oriented) $\times$ display type 
Table 2

Experiment 2: Mean Percentage of False Detections (FD) and of Correct Target Detections (CD), Mean $d^{\prime}$ and Beta Scores for Each Type of Display, and Mean Estimates of Illusory Conjunctions (IC), in Left (LVF) and Right (RVF) Visual Fields, and for Each Target

\begin{tabular}{|c|c|c|c|c|c|c|c|c|c|c|c|c|c|c|c|c|}
\hline \multirow[b]{3}{*}{ Type of Display } & \multicolumn{8}{|c|}{ LVF } & \multicolumn{8}{|c|}{ RVF } \\
\hline & \multicolumn{2}{|c|}{ FD } & \multicolumn{2}{|c|}{$\mathrm{CD}$} & \multicolumn{2}{|c|}{$d^{\prime}$} & \multicolumn{2}{|c|}{ Beta } & \multicolumn{2}{|c|}{ FD } & \multicolumn{2}{|c|}{$C D$} & \multicolumn{2}{|c|}{$d^{\prime}$} & \multicolumn{2}{|c|}{ Beta } \\
\hline & $M$ & $S D$ & $\bar{M}$ & $S D$ & $M$ & $S D$ & $M$ & $S D$ & $M$ & $S D$ & $\underline{M}$ & $S D$ & $M$ & $S D$ & $M$ & $S D$ \\
\hline $\begin{array}{l}\text { Inside } \\
\text { E large outside }\end{array}$ & $\begin{array}{l}26.2 \\
20.8\end{array}$ & & $\begin{array}{l}86.3 \\
77\end{array}$ & & $\begin{array}{l}2.15 \\
1.91\end{array}$ & & $\begin{array}{l}0.63 \\
1.20\end{array}$ & & $\begin{array}{l}23.7 \\
19.7\end{array}$ & & $\begin{array}{l}82.8 \\
76.6\end{array}$ & & $\begin{array}{l}2.08 \\
1.99\end{array}$ & & $\begin{array}{l}0.69 \\
1.18\end{array}$ & \\
\hline All & 23.7 & 12.9 & 81.8 & 14.4 & 2.04 & 0.74 & 0.87 & 4.51 & 20.9 & 16.5 & 79.8 & 16.2 & 2.04 & 0.66 & 0.90 & 5.11 \\
\hline $\begin{array}{l}\text { Inside } \\
\text { C large outside }\end{array}$ & $\begin{array}{l}11.7 \\
12.2\end{array}$ & & $\begin{array}{l}81 \\
77.2\end{array}$ & & $\begin{array}{l}2.55 \\
2.36\end{array}$ & & $\begin{array}{l}1.42 \\
2.02\end{array}$ & & $\begin{array}{l}14 \\
11.6\end{array}$ & & $\begin{array}{l}79.8 \\
78\end{array}$ & & $\begin{array}{l}2.44 \\
2.33\end{array}$ & & $\begin{array}{l}2.00 \\
1.84\end{array}$ & \\
\hline All & 12.2 & 14.6 & 79.3 & 15.3 & 2.46 & 0.67 & 1.69 & 5.35 & 12 & 13.1 & 79 & 13.4 & 2.38 & 0.59 & 1.92 & 4.09 \\
\hline IC & $11.5^{*}$ & 12.1 & & & $0.42 *$ & 0.8 & & & $8.9^{*}$ & 13.3 & & & $0.34 *$ & 0.77 & & \\
\hline $\begin{array}{l}\text { Inside } \\
\text { E small outside }\end{array}$ & $\begin{array}{l}28.7 \\
26.5\end{array}$ & & $\begin{array}{l}89.8 \\
83.8\end{array}$ & & $\begin{array}{l}2.15 \\
1.98\end{array}$ & & $\begin{array}{l}0.39 \\
0.88\end{array}$ & & $\begin{array}{l}30 \\
19.5\end{array}$ & & $\begin{array}{l}87.7 \\
80\end{array}$ & & $\begin{array}{l}2.04 \\
2.08\end{array}$ & & $\begin{array}{l}0.35 \\
1.08\end{array}$ & \\
\hline $\begin{array}{l}\text { Al! } \\
\text { Inside } \\
\text { C small outside }\end{array}$ & $\begin{array}{l}27.6 \\
17.3 \\
17.1\end{array}$ & 19.9 & $\begin{array}{l}86.8 \\
90.4 \\
82.9\end{array}$ & 11.5 & $\begin{array}{l}2.07 \\
2.66 \\
2.36\end{array}$ & 0.68 & $\begin{array}{l}0.58 \\
0.49 \\
0.95\end{array}$ & 4.18 & $\begin{array}{l}25 \\
14.6 \\
13.6\end{array}$ & 19 & $\begin{array}{l}84 \\
84.5 \\
78.2\end{array}$ & 14.4 & $\begin{array}{l}2.06 \\
2.48 \\
2.27\end{array}$ & 0.69 & $\begin{array}{l}0.62 \\
0.83 \\
1.45\end{array}$ & 4.22 \\
\hline $\begin{array}{l}\text { All } \\
\text { IC }\end{array}$ & $\begin{array}{l}17.2 \\
10.4^{*}\end{array}$ & $\begin{array}{l}14.2 \\
12.9\end{array}$ & 86.8 & 12.8 & $\begin{array}{l}2.51 \\
0.44 *\end{array}$ & $\begin{array}{l}0.77 \\
0.8\end{array}$ & 0.68 & 5.01 & $\begin{array}{l}14.4 \\
10.6^{*}\end{array}$ & $\begin{array}{l}12.8 \\
11.8\end{array}$ & 81.6 & 14.7 & $\begin{array}{l}2.38 \\
0.32 *\end{array}$ & $\begin{array}{l}0.57 \\
0.73\end{array}$ & 1.10 & 4.93 \\
\hline
\end{tabular}

Note $-\mathrm{E}=$ experimental displays, $\mathrm{C}=$ control displays, $\mathrm{IC}=$ illusory conjunctions. ${ }^{*} p<.005$.

(E vs. C) $\times$ hemifield (RVF vs. LVF) $\times$ size (large vs. small target and relevant material) was performed. There was a main effect of display type: the $d^{\prime}$ scores were smaller for $\mathrm{E}(2.06)$ than for $\mathrm{C}(2.42)$ displays $[F(1,46)=$ $61.34, p<.0011$. As shown in Table 2, this display type effect was significant for each combination of size and hemifield. However, neither the main effects of size and hemifield nor the size $\times$ hemifield interaction came out significantly $(F<1)$. Indeed, mean $d^{\prime}$ scores for the large target were 2.25 in LVF and 2.21 in RVF, and for the small target, 2.29 and 2.22 , respectively. Still, as expected, we observed a significant effect of context $[F(1,46)=5.01, p<.03]$, showing that overall discriminability is better with similarly (2.18) than with differentially (2.30) oriented contexts. In addition, there was no significant effect of position $[F(1,46)=3.03, p>$ $.085]$, and all of the interactions involving this factor were nonsignificant $(p<.10)$.

Correct detections. Mean CD scores are presented in Table 2. The ANOVA performed on CDs, with the same factors as in the $d^{\prime}$ analysis, revealed main effects of size [large target, $80 \%$; small target, $84.8 \% ; F(1,46)=9.12$, $p<.001$ ], hemifield [RVF, 81.1\%; LVF, 83.7\%; $F(1,46)=4.48, p<.04]$, and display type $[\mathrm{E}, 83.1 \%$; C, $81.7 \% ; F(1,46)=5.16, p<.03$ ], as well as a main effect of position: rectangles inside triangles yielded better performance than did rectangles outside triangles [ $84.4 \%$ vs. $79.4 \%$, respectively; $F(1,46)=5.99, p<.02$ ] However, the hemifield $x$ size interaction was not significant $[F(1,46)=1.52, p>.10]$.

False detections and illusory conjunctions. Table 2 presents mean FDs and mean ICs. An ANOVA was performed on FDs, with the same factors as in previous analyses. The display type effect was significant $[F(1,46)=$
$124.69, p<.001]$ : FDs were more numerous for $\mathrm{E}$ $(24.3 \%)$ than for C (13.9\%) displays, indicating occurrence of ICs. As shown in Table 2, the estimate of ICs was significant for each combination of size and hemifield. Context type was also significant $[F(1,46)=36.44, p<$ .0011 : There were more ICs with differentially oriented $(20.8 \%)$ than with similarly oriented $(17.5 \%)$ context displays. Context and display type interacted $[F(1,46)=$ $5.95, p<.02$ ]: Context had no effect on E displays (25.4\% for differentially oriented displays vs. $23.2 \%$ for similarly oriented displays), whereas for C displays, differentially oriented context yielded more FDs than did similarly oriented context $(16.2 \%$ vs. $11.7 \%$, respectively). Finally, there was a position $\times$ display type interaction: Fewer ICs were obtained with outside position than with inside position $[8 \%$ vs. $12.8 \% ; F(1,46)=6.59$, $p<.02]$.

Comparisons of Experiments 1 and 2. Three ANOVAs of experiment (Experiment 1 vs. Experiment 2) $\times$ group (material conditions) $\times$ display type $\times$ hemifield $\times$ size were conducted. The expected interaction experiment $\times$ hemifield $\times$ size was significant in both the analysis of $d^{\prime}$ scores $[F(1,76)=6.93, p<.02]$ and of CDs $[F(1,76)=10.11, p<.005]$. In addition, the interaction display type $\times$ experiment $\times$ hemifield $\times$ size, which concerns ICs, was not significant either in the analysis of $d^{\prime}$ scores or in the analysis of FDs $(F<1$ in both analyses).

\section{Discussion}

In this experiment, we presented simultaneously large and small forms. Contrary to what was observed in Experiment 1 , neither CDs nor $d^{\prime}$ scores showed the interaction between size and hemifield. The observation of lateral asymmetries in Experiment 1 but not in Experi- 
ment 2 suggests that the lateralization effect observed in the former experiment was not due to the fact that the observer had to detect a target of a particular size but rather to an unbalanced hemispheric activation of the integrative mechanisms due to the presentation of either small or large forms only. In other words, the relative activation of the two hemispheres depends on the total information available in the display rather than solely on the information that is relevant to the task. The fact that in Experiment 2 overall discriminability was negatively affected by the variability of the irrelevant context reinforces the notion that even uninformative, irrelevant information was taken into account.

\section{GENERAL DISCUSSION}

The present work attempted to assess whether feature analysis or, instead, integration of the analyzed features is the earliest lateralized stage in visual processing. A situation that should produce hemifield differences according to the notion of differential hemispheric specialization for the processing of large and small forms was designed. The principle of our manipulations consisted in comparing laterality for CDs and ICs, mainly in terms of a measure of perceptual discriminability, $d^{\prime}$. Before examining this issue, we will discuss the laterality findings and the ICs data separately.

\section{Hemispheric Specialization}

Sergent (1982) obtained RVF and LVF superiorities for the identification of small and large letters, respectively. On the basis of these and other data, she proposed that the left hemisphere is preferentially sensitive to high spatial frequencies, whereas the right hemisphere deals with low spectral information. In the present study, we also varied the size of the targets. It is beyond doubt that size had an effect on laterality, regardless of whether this effect was or was not mediated by differential spectral information. Indeed, in Experiment 1, there was an LVF superiority for the detection of the large target and an RVF superiority for the detection of the small target.

We are aware of the fact that several studies have not reported the same relation between laterality and size as indicated above (see, e.g., Michimata \& Hellige, 1987; Pitblado, 1979; Pring, 1981). Thus, although we describe the present findings in terms of the size of the targets, we do not intend to claim that this variable uniquely determines laterality. Our objective, with regard to laterality, was simply to find a situation that could elicit opposite asymmetrical effects.

In Experiment 1, the displays consisted of six identical forms, in same or different orientation, with, in some cases, one of these forms being replaced by the target. We observed that large materials yielded better CDs and higher overall $d^{\prime}$ scores when presented to the LVF than to the RVF, whereas a reverse pattern arose for small materials. Since the size of the two forms and targets (triangles and star vs. rectangles and cross) was reversed across group conditions, we may confidently conclude that the most crucial factor was size (or some variable highly correlated with size) rather than form. Moreover, the fact that these results were observed for the overall $d^{\prime}$ scores suggests that the size effect on laterality differences did not result from a response bias.

When the two sets of forms were presented simultaneously on each display (Experiment 2), with small forms either included in the larger ones or next to them, there was no interaction between target size and hemifield. The perceptual organization of small and large forms seems to be irrelevant. The lack of differential hemispheric asymmetry in the processing of large and small matęrials was observed both when spatial inclusion produced a systematic relation between forms and when small and large forms were presented side by side in a pseudorandom way. This suggests that the lateralization effect observed in Experiment 1 was not due to the fact that the observer had to detect a target of a particular size. Yet, how may one relate the discrepant results of the two experiments to the laterality literature?

Many studies used small forms presented as parts or features of larger forms. This is the case, for example, when a large global letter results from the spatial arrangement of small local letters. When the identity of the small and large letters conflict (e.g., a large $\mathbf{H}$ made of small Ss), the most frequent outcome is a superiority of the RVF for local processing and of the LVF for global processing. However, when they do not conflict (e.g., a large $\mathrm{H}$ made of small $\mathrm{Hs}$ ), or when the small letters never play the role of the target, the laterality effects are much less clear (see Van Kleeck, 1989, for a review). Thus, the occurrence of lateral asymmetry might be contingent on attending to a particular size, either because all the forms presented are of the same size (as it is the case in our Experiment 1) or because the task requires and allows attentional filtering (Garner, 1974; Posner, 1964) of stimuli of a particular size (this is the case of conflicting situations in compound-letter studies).

The hypothesis that attentional filtering strategies are responsible for lateral asymmetry is consistent with the notion that what matters for the determination of laterality effects is not only the stimuli actually presented to the observers but also, or even rather, what observers have to do or can do with the stimuli (Morais, 1982). However, attentional filtering cannot account for all lateralization processes. Its application is restricted to situations in which strategic processes are allowed. The possibility of attending selectively to particular subsets of stimuli is open to debate in array-size dependent search experiments (see, e.g., Egeth, Virzi, \& Garbart, 1984; Francolini \& Egeth, 1979; Kahneman \& Henik, 1977, 1981; Pashler, 1987; Treisman, 1982). In a search situation such as the one we used, masking before and after stimulus presentation, as well as very short exposure durations, most probably drastically reduce the intervention of filtering strategies of the irrelevant information. In such a situation, large versus small laterality integrative effects may 
thus appear only when one spatial scale is present in the stimuli, as in Experiment 1 . When different spatial scales intervene, and even if task requirements only address one particular scale, both hemispheres would be equally involved, and so no laterality difference would emerge. This is what we observed in Experiment 2. The effect of the variability of the irrelevant context (i.e., small rectangles for the large star target or large triangles for the small cross target) observed in Experiment 2 reinforces the notion that observers are unable to ignore irrelevant information.

To conclude, integration may operate differently in the two hemispheres, depending, among other things, on whether it concerns features from small or large forms. Yet the mechanism of integration would be sensitive to the size of forms that, despite being irrelevant to the task, are present in the display. When the situation impedes attentional filtering, and when different spatial scales are presented, integrative mechanisms of both hemispheres would be equally involved.

\section{Illusory Conjunctions}

Significant rates of ICs were obtained in both experiments. However, given that ICs might be a mere consequence of response biases causing observers to report the presence of the target more often in some kinds of displays than in others, it was important to draw our conclusions from $d^{\prime}$ scores rather than from raw FD data. In the two experiments, the analysis of $d^{\prime}$ scores was consistent with the analysis of FDs: Lower $d^{\prime}$ scores were found on $\mathrm{E}$ than on $\mathrm{C}$ displays, for both the star and the cross targets.

Given both the forms used and the conditions in which they were presented, it is possible to derive several interesting suggestions about the mechanism of ICs from the present results. One of these suggestions concerns the possible role of a particular kind of spatial relationnamely, spatial inclusion-on the IC phenomenon. Can ICs occur when the target components are included within different forms? Conversely, can an illusory target be created by combining forms that include other forms? Spatial inclusion was present in the displays of one condition of Experiment 2. Both the IC estimates and the $d^{\prime}$ scores obtained in this experiment show, on the one hand, that illusory crosses can be created by the incorrect conjunction of two rectangles despite the inclusion of each rectangle within a triangle, and, on the other hand, that illusory stars can be created by the incorrect conjunction of two triangles despite the fact that each triangular area includes a small rectangle. Thus, spatial inclusion does not seem to prevent the occurrence of ICs of either the inner or the outer forms. This aspect of our data reinforces and generalizes the observation made by Prinzmetal (1981) that encircled vertical segments may combine with encircled horizontal ones to form illusory plus signs (see also Gallant \& Garner, 1988).

Even if spatial inclusion does not prevent ICs, it could affect their occurrence by leading the inner and the outer forms (or at least some of their components) to stick together, thus making features at the same spatial scale harder to conjoin. This possibility can be tested by comparing the two conditions used in Experiment 2: rectangles inside versus outside the triangles. The results did not show a lower rate of ICs for the inside condition, either in terms of FDs or in terms of discriminability. Thus, spatial inclusion does not hinder the occurrence of ICs.

A second suggestion arising from the present results is that the size of the material does not influence the rate of ICs. Since we kept the size of the whole display constant, the size of the individual forms (either small or large triangles, or small or large rectangles) and the distance between their contours were negatively correlated: small forms were more distant from each other than were large forms. However, we did not observe distance (or size) effects on ICs, as measured by $d^{\prime}$ scores. This result is inconsistent with both Prinzmetal and Keysar's (1989) and Wolford's (1975) proposal that ICs should occur more readily between items that are close together than between items that are further apart. Yet, it corroborates Treisman and Schmidt's (1982) observations that spatial separation has little effect on the frequency of ICs (see more precise discussions in Cohen \& Ivry, 1989, 1991).

A third point deserving discussion concerns the nature of the units involved in ICs. It seems unlikely that the ICs obtained in the present study resulted only from combinations of independent single-line segments. If such an exhaustive analysis had occurred, we should have observed no significant rate of ICs for the star target or at least a lower rate than for the cross. Indeed, if information about the relative position of the individual lines is not preserved in preattentive analysis, then the similarly oriented triangles of control displays contained all the six single-lines necessary to form a Star of David. That was not the case for the cross. Provided that length and orientation of single lines is preserved, the cross could not be perceived by combining single segments of similarly oriented rectangles. In the present experiments, illusory stars occurred as frequently as did illusory crosses. Thus, the mere occurrence of illusory stars, and, what is more, the fact that they were as frequent as illusory crosses, suggest either that the relative position of line segments is encoded or, more speculatively, that the ICs observed here involve global forms (i.e., triangles for the star, rectangles for the cross) rather than independent single lines. There are at least two reasons to prefer the first notion. First, individual lines of triangles were shown to be analyzed preattentively. Since they conjoin with other forms to create ICs as often as spatially separate segments, they do not seem to "stick together" at all (Kolinsky, 1989; Treisman \& Paterson, 1984). Second, early extraction of some kind of emergent or configurational information may account for the preservation of the relative position of the triangle segments. ${ }^{4}$ In any event, the present results suggest that the features analyzed and then integrated by the perceptual system need not be physically simple, such as straight lines. This possibility was previously demon- 
strated by Treisman and Paterson (1984), who showed that some emergent features such as closure may be preattentively extracted (see replication in Kolinsky \& Morais, 1986).

\section{Illusory Conjunctions and Hemispheric Asymmetry}

Although ICs were consistently obtained in this study, their rate never varied significantly as a function of hemifield. In particular, in Experiment 1, in which both overall discriminability (overall $d^{\prime}$ scores on both $\mathrm{E}$ and $C$ displays) and CDs showed laterality differences, the crucial interaction of target, hemifield, and display type showed $F$ values lower than 1 . Thus, a clear dissociation regarding cerebral laterality appears between correct integration and ICs. Although early preattentive processes of feature extraction are not lateralized, feature integration may operate differently in the two hemispheres.

\section{Conclusion}

Whatever the exact factors that cause integration to operate differently in the two hemispheres, the main suggestion from the present study is that hemispheric asymmetries in visual perception may arise from the action of an integrative process.

This integrative process may be focal attention, in the sense used by Treisman in her feature integration theory of attention (Treisman, 1988). The link between attention and correct feature integration has been documented by both experimental studies and pathology. Attentional manipulations seem to affect the rate of ICs (Briand \& Klein, 1987; Prinzmetal, Presti, \& Posner, 1986; Treisman, 1985; Treisman \& Schmidt, 1982), but methodological problems make these studies inconclusive (see discussions in Tsal, 1989a, 1989b, as well as in Briand \& Klein, 1989; see also Navon, 1990a, 1990b, and Treisman, 1990). Yet more recent observations on brain-damaged patients strongly reinforce the notion that attention is crucial for visual feature integration. Indeed, brain-damaged subjects who have been shown to have difficulty in attending to stimuli presented on the side contralateral to their lesion (see, e.g., Posner, Walker, Friedrich, \& Rafal, 1984) exhibit a massive feature integration deficit for contralateral displays relative to ipsilateral ones: They experience both more ICs (Arguin, 1990; Arguin, Cavanagh, \& Joanette, in press; Cohen \& Rafal, 1991) and an impairment of the serial processing of conjunctive targets (Arguin, 1990; Arguin, Joanette, \& Cavanagh, in press).

The present view of focal attention as a process that operates differentially in the two hemispheres contradicts Eglin's (1987) conception of attention lateralization. However, it is consistent with Palmer and Tzeng's (1990) proposition that the occurrence of lateral asymmetry may be related to the use of either local (left hemispheric) or global (right hemispheric) search strategies. In their same-different tasks, these authors observed that when serial processing was involved, RVF errors linearly increased with display size, which suggests a strictly sequential item-by-item search strategy, whereas LVF error patterns were less consistent, probably resulting from parallel processing within groups of items. ${ }^{5}$

Of course, the commitment to Treisman's (1986b) theory in the interpretation of the present set of data must be considered as provisional. It is subject to converging evidence from a large variety of tasks and stimuli. Such evidence, if obtained, would suggest that the original inducer of laterality is the attentional, integrative component of perception.

\section{REFERENCES}

Arguin, M. (1990). Relation entre les déficits de l'attention et de la perception visuelle dans le cas d'une lésion cérébrale de l'hémisphère gauche chez l'humain [Relationship between attentional disorders and visual perception in the case of a cerebral lesion of the left hemisphere in the human]. Unpublished doctoral dissertation, University of Montreal, Montreal.

arguin, M., Cavanagh, P., \& Joanette, Y. (in press). Visual feature integration with an attention deficit. Brain \& Cognition.

arguin, M., Joanette, Y., Cavanagh, P. (1990). Comparing the cerebral hemispheres on the speed of spatial shifts of visual attention: Evidence from serial search. Neuropsychologia, 28, 733-736.

ARguin, M., Joanette, Y., \& CavanaGh, P. (in press). Visual search for feature and conjunction targets with an attention deficit. Journal of Cognitive Neuroscience.

ATTNEAVE, F. (1968). Triangles as ambiguous figures. American Journal of Psychology, 81, 447-453.

Briand, K. A., \& Klein, R. M. (1987). Is Posner's "beam" the same as Treisman's "glue"??: On the relation between visual orienting and feature integration theory. Journal of Experimental Psychology: Human Perception \& Performance, 13, 228-241.

Briand, K. A., \& KLEIN, R. M. (1989). Has feature integration theory come unglued? A reply to Tsal. Joumal of Experimental Psychology: Human Perception \& Performance, 15, 401-406.

Chmiel, N. (1989). Response effects in the perception of conjunctions of colour and form. Psychological Research, 51, 117-122.

COHEN, A., \& IVRY, R. B. (1989). Illusory conjunctions as a function of distance between objects inside and outside the focus of attention. Journal of Experimental Psychology: Human Perception \& Performance, 15, 650-663.

COHEN, A., \& IVRY, R. B. (1991). Density effects in conjunction search: Evidence for a coarse location mechanism of feature integration. Journal of Experimental Psychology: Human Perception \& Performance, 17, 891-901.

Cohen, A., \& Rafal, R. D. (1991). Attention and feature integration: Illusory conjunctions in a patient with a parietal lobe lesion. Psychological Science, 2, 106-110.

Duncan, J., \& Humphreys, G. W. (1989). A resemblance theory of visual search. Psychological Review, 96, 433-458.

DUNCAN, J., \& HumPHREYS, G. W. (1992). Beyond the search surface: Visual search and attentional engagement. Journal of Experimental Psychology: Human Perception \& Performance, 18, 578-588.

EgETh, H., VIRZI, R., \& GarbarT, H. (1984). Searching for conjunctively defined targets. Journal of Experimental Psychology: Human Perception \& Performance, 10, 32-39.

EGLIN, M. (1987). The effects of different attentional loads on feature integration in the cerebral hemispheres. Perception \& Psychophysics, 42, 81-86.

FoDor, J. A. (1983). The modularity of mind: An essay on faculty psychology. Cambridge, MA: MIT Press.

Francolini, C. M., \& Egeth, H. E. (1979). Perceptual selectivity is task dependent: The pop-out effect poops out. Perception \& Psychophysics, 25, 99-110.

Gallant, J. L., \& Garner, W. R. (1988). Some effects of distance and structure on conjunction errors. Bulletin of the Psychonomic Society, 26, 323-326.

GARNER, W. R. (1974). The processing of information and structure. Potomac, MD: Erlbaum. 
Green, D. M., \& Swets, J. A. (1966). Signal detection theory and psychophysics. New York: Wiley.

HECAEN, H. (1984). Les gauchers: Etude neuropsychologique. Paris: Presses Universitaires de France.

Hovck, M. R., \& Hoffman, J. E. (1986). Conjunction of color and form without attention: Evidence from an orientation-contingent color aftereffect. Journal of Experimental Psychology: Human Perception \& Performance, 12, 186-199.

Humphreys, G. W., Quinlan, P. T., \& RiDdoCh, M. J. (1989) Grouping processes in visual searches: Effects with single- and combined-feature targets. Journal of Experimental Psychology: General, 118, 258-279.

Humphreys, G. W., RidDoch, M. J., \& Quinlan, P. T. (1985). Interactive processes in perceptual organization: Evidence from visual agnosia. In M. I. Posner \& O. S. M. Marin (Eds.), Attention and performance $X I$ (pp. 301-319). Hillsdale, NJ: Erlbaum.

Kahneman, D., Henik, A. (1977). Effects of visual grouping on immediate recall and selective attention. In S. Dornic (Ed.), Attention and performance VI (pp. 307-332). Hillsdale, NJ: Erlbaum.

Kahneman, D., \& HeniK, A. (1981). Perceptual organization and attention. In M. Kubovy \& J. R. Pomerantz (Eds.), Perceptual organization (pp. 181-210). Hillsdale, NJ: Erlbaum

Kolinsky, R. (1988), La séparabilité des propriétés dans la perception des formes [The separability of properties in the perception of shapes]. Unpublished doctoral dissertation, Free University of Brussels, Brussels.

KoLINSKr, R. (1989). The development of separability in visual perception. Cognition, 33, 243-284

KolinSky, R., \& MoraIS, J. (1986). Evidence for early extraction of emergent properties in visual perception: A replication. Perceptual \& Motor Skills, 63, 171-174.

MARCEL, A. J. (1983). Conscious and unconscious perception: An approach to the relations between phenomenal experience and perceptual processes. Cognitive Psychology, 15, 238-300.

Michimata, C., \&ellige, J. (1987). Effects of blurring and stimulus size on the lateralized processing of nonverbal stimuli. Neuropsychologia, 25, 397-407.

Morais, J. (1982). The two sides of cognition. In J. Mehler, E. C. T. Walker, \& M. Garrett (Eds.), Perspectives on mental representation (pp. 277-309). Hillsdale, NJ: Erlbaum.

MordKoff, J. T., YANTIS, S., \& Egeth, H. E. (1990). Detecting conjunctions of color and form in parallel. Perception \& Psychophysics, 48, 157-168.

Moscovirch, M. (1979). Information processing in the cerebral hemispheres. In M. S. Gazzaniga (Ed.), Handbook of behavioral neurobiology: 2. Neuropsychology (pp. 379-446). New York: Plenum.

Navon, D. (1990a). Does attention serve to integrate features? Psychological Review, 97, 453-459.

Navon, D. (1990b). Treisman's search model does not require feature integration: Rejoinder to Treisman (1990). Psychological Review, 97, $464-465$.

PaLmer, S. E. (1980). What makes triangles point: Local and global effects in configurations of ambiguous triangles. Cognitive Psychology, 12, 285-305.

Palmer, T., \& Tzeng, O. J. L. (1990). Cerebral asymmetry in visual attention. Brain \& Cognition, 13, 46-58.

PaShler, H. (1987). Detecting conjunctions of color and form: Reassessing the serial search hypothesis. Perception \& Psychophysics, 41, 191-201.

PASHLER, H., \& BADGIO, P. (1985). Visual attention and stimulus identification. Journal of Experimental Psychology: Human Perception \& Performance, 11, 105-121.

Pitblado, C. B (1979). Cerebral asymmetries in random-dot stereopsis Reversal of direction with changes in dot size. Perception, 8, 683-690.

POSNER, M. I. (1964). Information reduction in the analysis of sequential tasks. Psychological Review, 71, 491-504.

Posner, M. I., Walker, J. A., Friedrich, F. J., \& Rafal, R. D (1984). Effects of parietal lobe injury on covert orienting of visual attention. Joumal of Neuroscience, 4, 1863-1874.

Pring, T. R. (1981). The effect of stimulus size and exposure duration on visual field asymmetries. Cortex, 17, 227-239.
Prinzmetal, W. (1981). Principles of feature integration in visual perception. Perception \& Psychophysics, 30, 330-340.

Prinzmetal, W., Keysar, B. (1989). Functional theory of illusory conjunctions and neon colors. Journal of Experimental Psychology: General, 118, 165-190.

Prinzmetal, W., Presti, D. E., \& Posner, M. I. (1986). Does attention affect visual feature integration? Journal of Experimental Psychology: Human Perception \& Performance, 12, 361-369.

QUINLAN, P. T., \& HUMPHREYS, G. W. (1987). Visual search for targets defined by combinations of color, shape, and size: An examination of the task constraints on feature and conjunction searches. Perception \& Psychophysics, 41, 455-472.

SChOOLER, J. W., \& TANAKA, J. W. (1991). Composites, compromises, and CHARM: What is the evidence for blend memory representations? Journal of Experimental Psychology: General, 120, 96-100.

SERGENT, J. (1982). The cerebral balance of power: Confrontation or cooperation? Journal of Experimental Psychology: Human Perception \& Performance, 8, 253-272.

Titpens Reinitz, M., Lammers, W. J., \& Pitts Cochran, B. (1992). Memory-conjunction errors: Miscombination of stored stimulus features can produce illusions of memory. Memory \& Cognition, 20, 1-11.

TOWNSEND, J. T. (1971). A note on the identifiability of parallel and serial processes. Perception \& Psychophysics, 10, 161-163.

TOWNSEND, J. T. (1972). Some results on the identifiability of parallel and serial processes. British Journal of Mathematical \& Statistical Psychology, 25, 168-199.

Townsend, J. T., \& Ashry, F. G. (1983). Stochastic modeling of elementary psychological processes. Cambridge, U.K.: Cambridge University Press.

Treisman, A. (1982). Perceptual grouping and attention in visual search for features and for objects. Journal of Experimental Psychology: Human Perception \& Performance, 8, 194-214.

Treisman, A. (1985). Preattentive processing in vision. Computer Vision, Graphics \& Image Processing, 31, 156-177.

Treisman, A. (1986a). Properties, part and objects. In K. R. Boff, L. Kaufman, \& J. P. Thomas (Eds.), Handbook of perception and human performance (Vol. 2, pp. 35/1-35/70). Chichester, U.K.: Wiley.

Treisman, A. (1986b). Features and objects in visual processing. Scientific American, 255, 114-125.

Treisman, A. (1988). Features and objects: The fourteenth Bartlett Memorial Lecture. Quarterly Journal of Experimental Psychology, 40A, 201-237.

Treisman, A. (1990). Variations on the theme of feature integration: Reply to Navon (1990). Psychological Review, 97, 460-463.

Treisman, A. (1991). Search, similarity, and integration of features between and within dimensions. Journal of Experimental Psychology: Human Perception \& Performance, 17, 652-676.

Treisman, A. (1992). Spreading suppression or feature integration? A reply to Duncan and Humphreys (1992). Journal of Experimental Psychology: Human Perception \& Performance, 18, 589-593.

Treisman, A., \& Gelade, G. (1980). A feature integration theory of attention. Cognitive Psychology, 12, 97-136.

Treisman, A., Gormican, S. (1988). Feature analysis in early vision: Evidence from search asymmetries. Psychological Review, 95 , 15-48.

Treisman, A., \& Paterson, R. (1984). Emergent features, attention and object perception. Journal of Experimental Psychology: Human Perception \& Performance, 10, 12-21.

Treisman, A., \& Sato, S. (1990). Conjunction search revisited. Joumal of Experimental Psychology: Human Perception \& Performance, 16, 459-478.

Treisman, A., \& SCHMidT, H. (1982). Illusory conjunctions in the perception of objects. Cognitive Psychology, 14, 107-141.

Treisman, A., \& Souther, J. (1985). Search asymmetry: A diagnostic for preattentive processing of separable features. Journal of Experimental Psychology: General, 114, 285-310.

Treisman, A. \& SOUTHER, J. (1986). Illusory words: The roles of attention and of top-down constraints in conjoining letters to form words. Joumal of Experimental Psychology: Human Perception \& Performance, 12, 3-17. 
Treisman, A., Sykes, M., \& Gelade, G. (1977). Selective attention and stimulus integration. In S. Dornic (Ed.), Attention and performance $V I$ ( pp. 333-361). Hillsdale, $\mathrm{NJ}$ : Erlbaum.

TSAL, Y. (1989a). Do illusory conjunctions support the feature integration theory? A critical review of theory and findings. Journal of Experimental Psychology: Human Perception \& Performance, 15 , $394-400$.

TsaL, Y. (1989b). Further comments on feature integration: A reply to Briand and Klein. Journal of Experimental Psychology: Human Perception \& Performance, 15, 407-410.

VAN KLEECK, M. H. (1989). Hemispheric differences in global versus local processing of hierarchical visual stimuli by normal subjects: New data and a meta-analysis of previous study. Neuropsychologia, 27, 1165-1178.

Wolfe, J. M., CAVE, K. R., \& Franzel, S. L. (1989). Guided search: An alternative to the feature integration model for visual search. Journal of Experimental Psychology: Human Perception \& Performance, $15,419-433$.

Wolford, G. (1975). Perturbation model for letter identification. Psychological Review, 82, 184-199.

\section{NOTES}

1. Since central presentation was only used as a control condition and was irrelevant to our purpose, results concerning this condition were not included in the statistical analysis and will not be presented in the Results section.
2. Since $d^{\prime}$ scores go to infinity for probabilities of 1 and 0 , the $100 \%$ and $0 \%$ scores were arbitrarily replaced by $99 \%$ and $1 \%$ scores, respectively. This procedure allows comparisons of the different materials and conditions, but the absolute values for $d^{\prime}$ cannot be given much importance.

3. Beta values were not discussed in the Results section, since response biases were not relevant to our purpose. They will, however, be presented in the tables. Since the distribution of beta scores is extremely skewed, means were computed with natural logarithms. However, for a direct reading in Tables 1 and 2 , these means were transformed back into a beta scale with the exponential function.

4. The idea that some relative position information is encoded in our experiments, in which quasiequilateral triangles were used, may be related to the observation of both directional and configurational biases in the perception of ambiguous equilateral triangles (see, e.g., Attneave, 1968; Palmer, 1980). As a matter of fact, even if isolated equilateral triangles can be seen oriented in any of three directions consistent with the axes of symmetry, the observers in our experiments showed a marked bias toward perceiving them as being oriented to the vertical; moreover, axis or base alignment make them "point" in a particular direction.

5 . See similar suggestions of serial between-group and parallel withingroup processing (e.g., in Pashler, 1987, and in Treisman, 1982; but see also Arguin, Joanette, and Cavanagh, 1990, for other laterality data).

(Manuscript received May 21, 1992; revision accepted for publication April 2, 1993.) 